\title{
Changes in the epidemiology of sudden infant death syndrome in Sweden 1973-1996
}

\begin{abstract}
B Alm, S G Norvenius, G Wennergren, R Skjærven, N Øyen, J Milerad, M Wennborg, J Kjaerbeck, K Helweg-Larsen, L M Irgens, on behalf of the Nordic Epidemiological SIDS Study
\end{abstract}

Department of Paediatrics, Institute for the Health of Women and Children, Göteborg University, The Queen Silvia Children's Hospital, SE-416 85 Göteborg, Sweden

B Alm

S G Norvenius

G Wennergren

J Kjaerbeck

Medical Birth

Registry, University of Bergen, Bergen,

Norway

R Skjærven

$\mathrm{N}$ Øyen

L M Irgens

Department of Paediatrics,

Karolinska Hospital, Stockholm, Sweden

J Milerad

M Wennborg

Danish Institute of Clinical Epidemiology, Copenhagen, Denmark K Helweg-Larsen

Correspondence to: Dr Alm

bernt.alm@medfak.gu.se

Accepted 15 June 2000

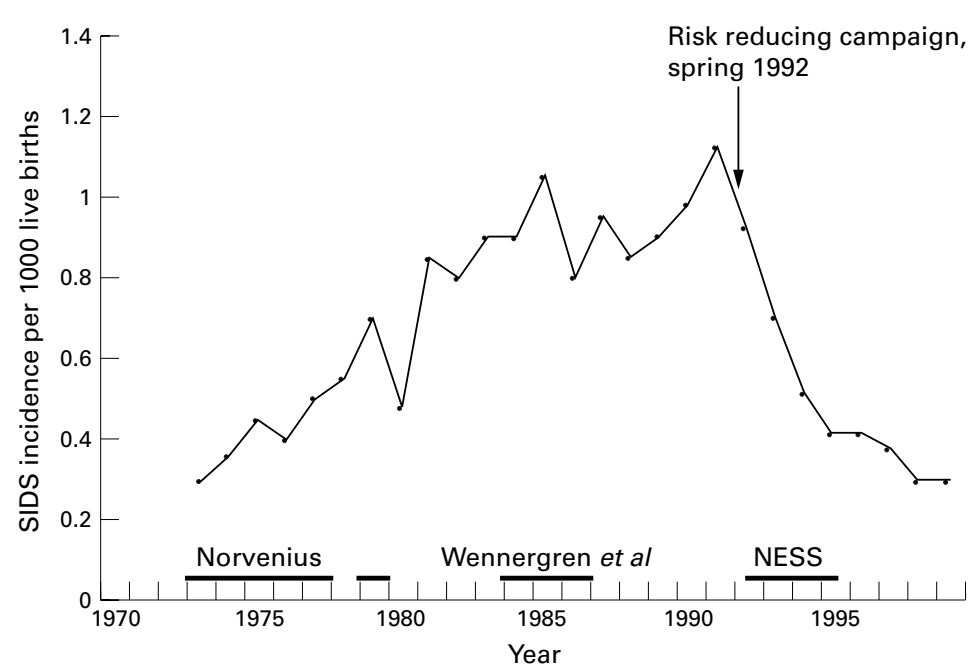

Figure 1 Incidence of SIDS in Sweden 1973-1999. Data from the Medical Birth Registry of Sweden. Time periods for studies mentioned in the text are indicated by bold lines.

\begin{abstract}
Background-From the early 1970s to the early 1990s, there was a significant rise in the incidence of sudden infant death syndrome (SIDS) in Scandinavia. Following the risk reducing campaign, the incidence has fallen to about the same level as in 1973.

Aims-To identify the changes that have occurred in the epidemiology of SIDS.

Methods-We compared the Swedish part of the Nordic Epidemiological SIDS Study (NESS), covering the years 1992-1995, with two earlier, descriptive studies during this period. To assess the changing effects of risk factors, we analysed data from the Medical Birth Registry of Sweden, covering the years 1973-1996.

Results-There was a predominance of deaths during weekends in the 1970 s and 1990s. The seasonal variation was most notable in the $1980 \mathrm{~s}$. The proportion of young mothers decreased from $14 \%$ to $5 \%$. Cohabitation (living with the biological father) was as frequent in the $1990 \mathrm{~s}$ as in the 1970s. The prevalence of high parity, admissions to neonatal wards, low birth weight, prematurity, and multiple pregnancies were all increased in the 1990 s compared to the $1970 \mathrm{~s}$. No significant change in the prevalence of previous apparent life threatening events was found. Deaths occurring in cars diminished from $10 \%$ to below $2 \%$. In the data from the Medical Birth Registry of Swe-
\end{abstract}

den, there were significantly increased odds ratios after the risk reducing campaign of the risk factors smoking during early pregnancy and preterm birth. We could find no increased effects of maternal age, parity, or being small for gestational age over time. The rate of deaths at weekends remained increased; the median age at death fell from 90 to 60 days. Seasonal variation was less notable in the periods of low incidence.

(Arch Dis Child 2001;84:24-30)

Keywords: SIDS; epidemiology; Sweden

Since the beginning of the 1970s studies have described the epidemiology of sudden infant death syndrome (SIDS) in Sweden. Petersson and von Sydow investigated the phenomenon between 1968 and 1972 in seven counties in Sweden, and found a mean incidence of 0.56 per 1000 live births. ${ }^{1}$ Norvenius' thesis comprised the birth cohorts of 1973-1977 and $1979 .^{2}$ In the beginning of his study, the incidence was low, around 0.4 per 1000 live births, but at the end it had already begun to rise slowly; in 1979 the figure was 0.7 per 1000 (fig 1). It had almost reached its maximum (1.1 in 1991) in 1984-1986, when Wennergren et al investigated 70 cases of SIDS from the four largest urban areas and one rural area in Sweden, and found an incidence of 0.9 per 1000 live births. ${ }^{3}$ The Nordic Epidemiological SIDS Study (NESS), which comprised SIDS cases and controls in Denmark, Norway, and Sweden, covered the years between 1992 and 1995. In the first part of the present study, we have compared the epidemiological characteristics of the cases in Norvenius' and Wennergren's studies with the Swedish cases in the NESS.

Following the reporting of prone sleeping as a risk factor for SIDS,,$^{5-7}$ campaigns for supine sleeping were introduced in Scandinavia. This was done in 1990 in Norway, ${ }^{8}$ in 1991 in Denmark, ${ }^{9}$ and in April 1992 in Sweden. ${ }^{10}$ These campaigns were followed by a dramatic drop in the incidence in all three countries. ${ }^{11} \mathrm{In}$ a previous paper based on NESS data, ${ }^{11}$ we have reported increasing effects over time (1992-1995) of prone sleeping, maternal smoking, and bottle feeding following the campaign.

In a recent study from Norway, ${ }^{12}$ increasing effects of low maternal age and high birth order on SIDS were observed throughout the period 1967-1993, regardless of the changes in SIDS 
Table 1 Epidemiological characteristics of SIDS cases in three studies in Sweden

\begin{tabular}{lllll}
\hline Study & $\begin{array}{l}\text { Norvenius } \\
\text { 1973-1977 + 1979 } \\
(n=334)\end{array}$ & $\begin{array}{l}\text { Wennergren et al } \\
1984-1986 \\
(n=70)\end{array}$ & $\begin{array}{l}\text { NESS/Sweden } \\
1992-1995 \\
(n=117)\end{array}$ & $p$ value \\
\hline SIDS incidence (per 1000 live births) & 0.5 & 0.9 & 0.6 & - \\
Weekends (Sat + Sun) (\%) & 38.0 & - & 36.8 & 0.81 \\
Maternal age <20 years (\%) & 13.6 & - & 5.1 & 0.014 \\
Cohabitation & 91.0 & - & 41.0 & 0.68 \\
Parity 3+ (\%) & 28.4 & - & 29.9 & 0.012 \\
Neonatal ward (\%) & 16.5 & - & 22.2 & 0.002 \\
Birth weight <2500 g (\%) & 3.8 & - & 29.1 & $<0.001$ \\
Gestational age <38 weeks (\%) & 14.7 & $1.4+/ 4.3 \ddagger$ & 6.0 & 0.001 \\
Multiple births (\%) & 4.2 & 17.0 & 9.4 & 0.03 \\
Previous ALTE (\%) & 4.3 & 12.0 & 1.7 & 0.43 \\
Place of death outdoors (\%) & 11.1 & 39.0 & 35.0 & 0.25 \\
Place of death in car (\%) & 9.6 & - & & 0.014 \\
Recent cold (\%) & & &
\end{tabular}

*Twin or triplet. †True ALTE. $\ddagger$ Possible ALTE.

incidence. To see whether this was the case in Sweden as well, and to assess possible changes in the effects of other risk factors, we also studied case and control data from the Medical Birth Registry of Sweden. The records covered the whole period of medical birth registration in Sweden (1973-1996).

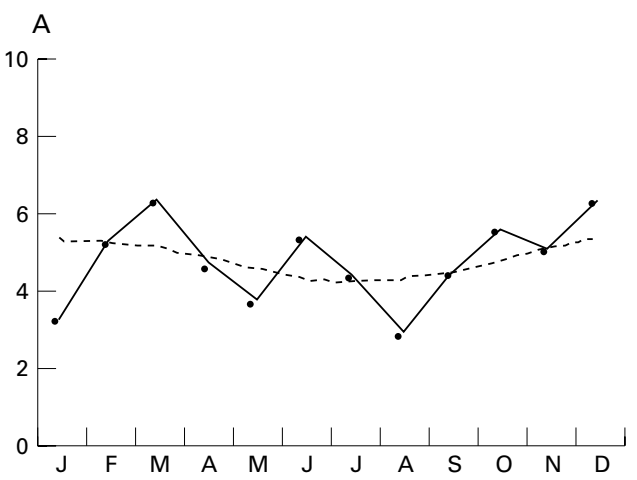

$$
\text { B }
$$

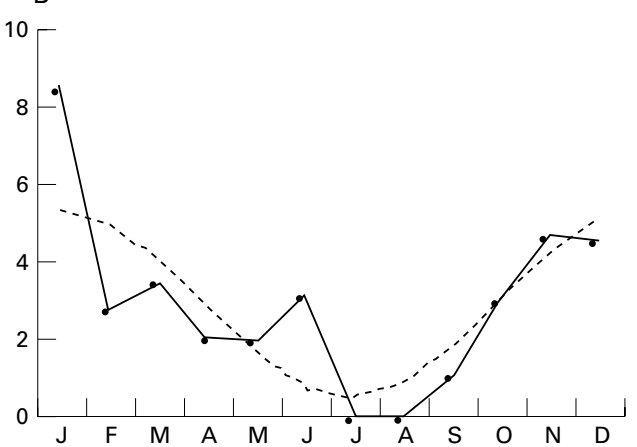

C

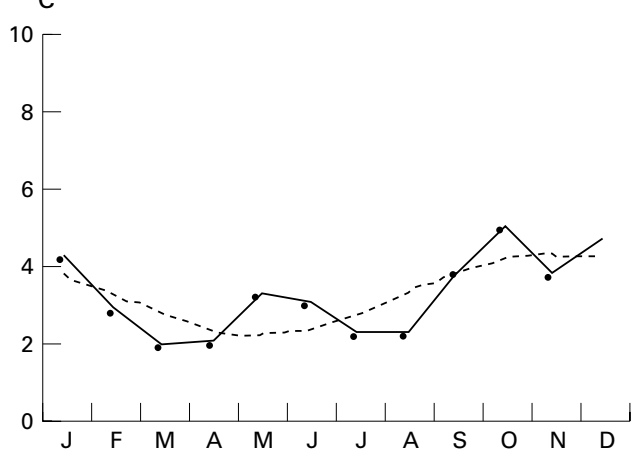

Figure 2 SIDS cases per month (continuous line) in the studies of (A) Norvenius, 1973-1977 + 1979; (B) Wennergren et al, 1984-1986; and (C) NESS, 1992-1995; and fitted cosine curve (dotted line).
The objectives of the present study were: (1) to compare epidemiological characteristics of SIDS in periods of high incidence with periods of low incidence; (2) to compare epidemiological characteristics of SIDS before and after the introduction of supine sleeping; and (3) to assess the effects of established risk factors before and after the introduction of supine sleeping.

\section{Subjects and methods}

\section{SUBJECTS}

In the first part of the study we compared the studies of Norvenius ${ }^{2}$ and Wennergren and colleagues $^{3}$ with the Swedish cases in the NESS study.

Norvenius $^{2}$ thoroughly examined 1837 postperinatal deaths on the basis of death certificates, police reports, autopsy protocols, medical records from the maternity wards, infant welfare clinics, and hospitals plus available records from social welfare bureaus. This resulted in data on 334 cases of SIDS from the birth cohorts of 1973-1977 and 1979 that was added because of a rising incidence. Of these 334 cases, $82(24.6 \%)$ were a result of reclassification with the aid of the sources mentioned above, and thus not included in official statistics. Wennergren and colleagues ${ }^{3}$ investigated 34 apparent life threatening events (ALTE) and 70 cases of SIDS from the four largest urban areas in Sweden (Stockholm, Göteborg/Mölndal, Malmö/Lund, and Uppsala) and the county of Värmland, by means of a standardised protocol. The early studies of Norvenius and Wennergren were descriptive, and thus no controls were recruited.

In the NESS, cases were collected between 1 September 1992 and 31 August 1995, resulting in 244 cases of SIDS and 869 controls. Data were collected by means of a postal questionnaire. The protocol is described in detail elsewhere. ${ }^{13}$ To allow comparison with the two earlier studies, only results concerning the Swedish cases $(n=117)$ are presented in this paper.

In the second part of the present study, data from the Medical Birth Registry (MBR) of Sweden, consisting of 1724 cases of SIDS and 24000 controls, 1000 from each year, were used to assess the effect of risk factors. Since the start of medical birth registration in $1973,{ }^{14}{ }^{15}$ the items of data registered have been 
Table 2 Unadjusted odds ratios of risk factors for SIDS and interaction with time period in Sweden 1973-1996

\begin{tabular}{|c|c|c|c|c|c|c|c|}
\hline & \multicolumn{2}{|c|}{$\begin{array}{l}\text { I. Rising incidence } \\
1973-1980 \\
(n=8372)\end{array}$} & \multicolumn{2}{|c|}{$\begin{array}{l}\text { II. High incidence } \\
1981-1992 \\
(n=13187)\end{array}$} & \multicolumn{2}{|c|}{$\begin{array}{l}\text { III. Falling incidence } \\
\text { 1993-1996 } \\
(n=4165)\end{array}$} & \multirow{2}{*}{$\begin{array}{l}\text { Interaction with time } \\
\text { period ( } p \text { value) }\end{array}$} \\
\hline & OR & $95 \% C I$ & OR & $95 \% C I$ & $O R$ & $95 \% C I$ & \\
\hline Smoking in early pregnancy & & & & & & & $<0.001$ \\
\hline Nil & - & - & 1.0 & ref & 1.0 & ref & \\
\hline 1-9 cigarettes per day & - & - & 1.9 & $1.6,2.2$ & 3.1 & $2.0,4.8$ & \\
\hline $10+$ cigarettes per day & - & - & 3.3 & $2.8,3.8$ & 9.6 & $6.5,14.0$ & \\
\hline Male sex & 1.4 & $1.1,1.7$ & 1.5 & $1.3,1.7$ & 1.2 & $0.9,1.7$ & 0.45 \\
\hline Maternal age & & & & & & & 0.09 \\
\hline$\leqslant 19$ years & 2.1 & $1.5,3.1$ & 2.2 & $1.7,2.8$ & 3.1 & $1.5,6.6$ & \\
\hline $20-24$ years & 1.3 & $1.0,1.7$ & 1.1 & $1.0,1.3$ & 1.6 & $1.1,2.4$ & \\
\hline $25-29$ years & 1.0 & ref & 1.0 & ref & 1.0 & ref & \\
\hline $30-34$ years & 1.1 & $0.8,1.4$ & 0.9 & $0.7,1.0$ & 0.7 & $0.4,1.1$ & \\
\hline $35+$ years & 0.8 & $0.5,1.4$ & 0.7 & $0.6,0.9$ & 1.3 & $0.8,2.1$ & \\
\hline Parity & & & & & & & 0.52 \\
\hline 1 & 1.0 & ref & 1.0 & ref & 1.0 & ref & \\
\hline 2 & 1.3 & $1.0,1.6$ & 1.8 & $1.5,2.0$ & 1.6 & $1.0,2.4$ & \\
\hline 3 & 1.6 & $1.1,2.1$ & 2.0 & $1.7,2.4$ & 2.8 & $1.8,4.3$ & \\
\hline $4+$ & 2.8 & $2.0,4.1$ & 3.0 & $2.4,3.7$ & 4.2 & $2.6,6.9$ & \\
\hline SGA & 2.2 & $1.5,3.2$ & 2.2 & $1.7,2.9$ & 1.6 & $0.7,3.8$ & 0.80 \\
\hline Preterm birth & 2.0 & $1,4,2.9$ & 2.0 & $1.6,2.4$ & 4.3 & $2.8,6.6$ & 0.005 \\
\hline SGA and preterm birth & 3.7 & $1.9,7.3$ & 2.6 & $1.6,4.4$ & 6.8 & $2.7,17.1$ & 0.19 \\
\hline
\end{tabular}

Data from the Medical Birth Registry of Sweden.

changed in some respects, mainly concerning smoking and marriage/cohabitation. In the years 1973-1986, SIDS was defined as ICD-8 code 795, and in the following years ICD-9 code 798 was used. There is no information about smoking before 1981. In the same period of time, births were classified as in or out of wedlock, which in 1982 was replaced with information about cohabitation with the biological father. These data were analysed both for each year and for periods with varying incidence. The periods chosen were 1973-1980 with a rising incidence (below 0.8 per 1000 live births), 1981-1992 with a high incidence (above 0.8 per 1000), and 1993-1996 with a falling incidence (below 0.8 per 1000) after the reintroduction of supine sleeping in 1992 (fig 1).

\section{METHODS}

Comparisons of two proportions were done by the $\chi^{2}$ method in the EpiInfo package, version $6.04 \mathrm{~b},{ }^{16}$ and of a single proportion according to Altman. ${ }^{17}$
Odds ratios (OR) were calculated by unconditional logistic regression, using the SPSS statistical software package. ${ }^{18}$ To evaluate the change of effect, the interaction term between each risk factor and period of time was calculated, both univariate and in a multivariate model.

Small for gestational age (SGA) was defined as a birth weight below -2 standard deviations from the mean expected for the gestational age as determined according to the current Swedish gestational age-growth curves. ${ }^{19}$ This resulted in $3.7 \%$ of the controls being classified as SGA $(5.6 \%$ in 1973 , declining to $2.8 \%$ in 1996).

Significant variables used in the models were: smoking during early pregnancy, male sex, maternal age, parity, SGA, preterm birth, and the combination of SGA and preterm birth. Apgar score and multiple birth were not significant in the models. Birth weight was included in the MBR data, but as this variable comprised both SGA infants and preterm appropriate for gestational age (AGA) infants,

Table 3 Adjusted odds ratios of risk factors of SIDS and interaction with time period in Sweden 1973-1996

\begin{tabular}{|c|c|c|c|c|c|c|c|}
\hline & \multicolumn{2}{|c|}{$\begin{array}{l}\text { I. Rising incidence } \\
1973-1980 \\
(n=8372)\end{array}$} & \multicolumn{2}{|c|}{$\begin{array}{l}\text { II. High incidence } \\
1981-1992 \\
(n=13187)\end{array}$} & \multicolumn{2}{|c|}{$\begin{array}{l}\text { III. Falling incidence } \\
\text { 1993-1996 } \\
(n=4165)\end{array}$} & \multirow{2}{*}{$\begin{array}{l}\text { Interaction with time } \\
\text { period ( } p \text { value) }\end{array}$} \\
\hline & OR & $95 \% C I$ & OR & $95 \% C I$ & OR & $95 \% C I$ & \\
\hline Smoking in early pregnancy & - & - & & & & & $<0.001$ \\
\hline Nil & & & 1.0 & ref & 1.0 & ref & \\
\hline 1-9 cigarettes per day & & & 1.6 & $1.4,1.9$ & 2.5 & $1.6,4.0$ & \\
\hline $10+$ cigarettes per day & & & 2.6 & $2.2,3.1$ & 7.6 & $5.0,11.4$ & \\
\hline Male sex & - & - & 1.6 & $1.4,1.9$ & 1.2 & $0.9,1.7$ & 0.12 \\
\hline Maternal age & - & - & & & & & 0.09 \\
\hline$\leqslant 19$ years & & & 3.3 & $2.5,4.5$ & 4.8 & $2.0,11.8$ & \\
\hline $20-24$ years & & & 1.4 & $1.2,1.6$ & 2.1 & $1.3,3.4$ & \\
\hline $25-29$ years & & & 1.0 & ref & 1.0 & ref & \\
\hline $30-34$ years & & & 0.7 & $0.6,0.8$ & 0.6 & $0.4,1.0$ & \\
\hline $35+$ years & & & 0.4 & $0.3,0.6$ & 0.9 & $0.5,1.5$ & \\
\hline Parity & - & - & & & & & 0.31 \\
\hline 1 & & & 1.0 & ref & 1.0 & ref & \\
\hline 2 & & & 2.3 & $2.0,2.8$ & 2.3 & $1.4,3.8$ & \\
\hline 3 & & & 3.0 & $2.4,3.7$ & 4.5 & $2.6,7.8$ & \\
\hline $4+$ & & & 5.2 & $4.0,6.7$ & 5.4 & $2.9,10.0$ & \\
\hline SGA & - & - & 2.2 & $1.6,3.1$ & 1.9 & $0.8,4.5$ & 0.70 \\
\hline Preterm birth & - & - & 1.7 & $1.4,2.2$ & 3.5 & $2.1,5.9$ & 0.012 \\
\hline SGA and preterm birth & - & - & 2.9 & $1.6,5.2$ & 11.5 & $4.0,33.3$ & 0.025 \\
\hline
\end{tabular}

Data from the Medical Birth Registry of Sweden. Model contained smoking in pregnancy (available in periods II and III only), male sex, maternal age, parity, SGA, preterm birth, and combined SGA and preterm birth. 
Table 4 Adjusted odds ratios of risk factors of SIDS and interaction with time period in Sweden 1973-1996

\begin{tabular}{|c|c|c|c|c|c|c|c|}
\hline & \multicolumn{2}{|c|}{$\begin{array}{l}\text { I. Rising incidence } \\
1973-1980 \\
(n=8372)\end{array}$} & \multicolumn{2}{|c|}{$\begin{array}{l}\text { II. High incidence } \\
1981-1992 \\
(n=13187)\end{array}$} & \multicolumn{2}{|c|}{$\begin{array}{l}\text { III. Falling incidence } \\
1993-1996 \\
(n=4165)\end{array}$} & \multirow{2}{*}{$\begin{array}{l}\text { Interaction with time } \\
\text { period ( } p \text { value) }\end{array}$} \\
\hline & $O R$ & $95 \% C I$ & $O R$ & $95 \% C I$ & $O R$ & $95 \% C I$ & \\
\hline Male sex & 1.4 & $1.1,1.7$ & 1.5 & $1.3,1.7$ & 1.2 & $0.9,1.7$ & 0.39 \\
\hline Maternal age & & & & & & & 0.08 \\
\hline$\leqslant 19$ years & 3.1 & $2.1,4.7$ & 4.0 & $3.0,5.2$ & 6.7 & $3.0,14.9$ & \\
\hline $20-24$ years & 1.7 & $1.3,2.2$ & 1.5 & $1.3,1.8$ & 2.4 & $1.5,3.6$ & \\
\hline $25-29$ years & 1.0 & ref & 1.0 & ref & 1.0 & ref. & \\
\hline $30-34$ years & 0.8 & $0.6,1.1$ & 0.7 & $0.6,0.8$ & 0.6 & $0.4,0.9$ & \\
\hline $35+$ years & 0.5 & $0.3,0.8$ & 0.4 & $0.3,0.6$ & 0.8 & $0.5,1.4$ & \\
\hline Parity & & & & & & & 0.13 \\
\hline 1 & 1.0 & ref & 1.0 & ref & 1.0 & ref & \\
\hline 2 & 1.7 & $1.3,2.2$ & 2.5 & $2.1,2.9$ & 2.3 & $1.5,3.6$ & \\
\hline 3 & 2.5 & $1.8,3.6$ & 3.5 & $2.9,4.3$ & 4.8 & $2.9,7.9$ & \\
\hline $4+$ & 5.6 & $3.7,8.5$ & 6.2 & $4.8,7.8$ & 6.5 & $3.7,11.5$ & \\
\hline SGA & 2.3 & $1.6,3.4$ & 2.7 & $2.0,3.6$ & 2.4 & $1.0,5.6$ & 0.83 \\
\hline Preterm birth & 2.1 & $1.4,3.0$ & 1.8 & $1.5,2.3$ & 3.9 & $2.5,6.2$ & 0.012 \\
\hline SGA and preterm birth & 4.2 & $2.1,8.4$ & 3.0 & $1.8,5.1$ & 7.3 & $2.7,19.3$ & 0.29 \\
\hline
\end{tabular}

Data from the Medical Birth Registry of Sweden. Model contained male sex, maternal age, parity, SGA, preterm birth, and combined SGA and preterm birth.

birth weight was omitted and replaced with combinations of SGA and preterm birth.

For the assessment of time trends in odds ratios for risk factors, linear regression and Pearson's R was used.

To assess seasonality in the early studies, as well as in the MBR data, we used the method of cosinor analysis described by Hallberg and colleagues ${ }^{20}$ and Douglas and colleagues. ${ }^{21}$ The function $f(\phi)=a+b \cos (\phi+c)$ was fitted to the data. $\phi$ is the angular value of the midpoint of the month (Jan $=2 \pi / 24, \mathrm{Feb}=3^{\star} 2 \pi / 24$, March $=5^{\star} 2 \pi / 24$, etc). The angular value of the peak is $(\pi-c)$ if $b<0$, and $(-c)$ if $b>0$, and $|\mathrm{a}|+|\mathrm{b}|$ is the maximal incidence at this value. According to Douglas and colleagues, ${ }^{21}$ the months were corrected to 31 days by multiplying February by 1.097 and April, June, September, and November by 1.033 .

\section{Results}

COMPARISON BETWEEN STUDIES

Table 1 presents the epidemiological characteristics of SIDS cases in the three studies in Sweden. The most significant changes among the SIDS cases were that low birth weight (less than $2500 \mathrm{~g}$ ) increased in frequency from $4 \%$ to $22 \%$, and that short gestational age (less

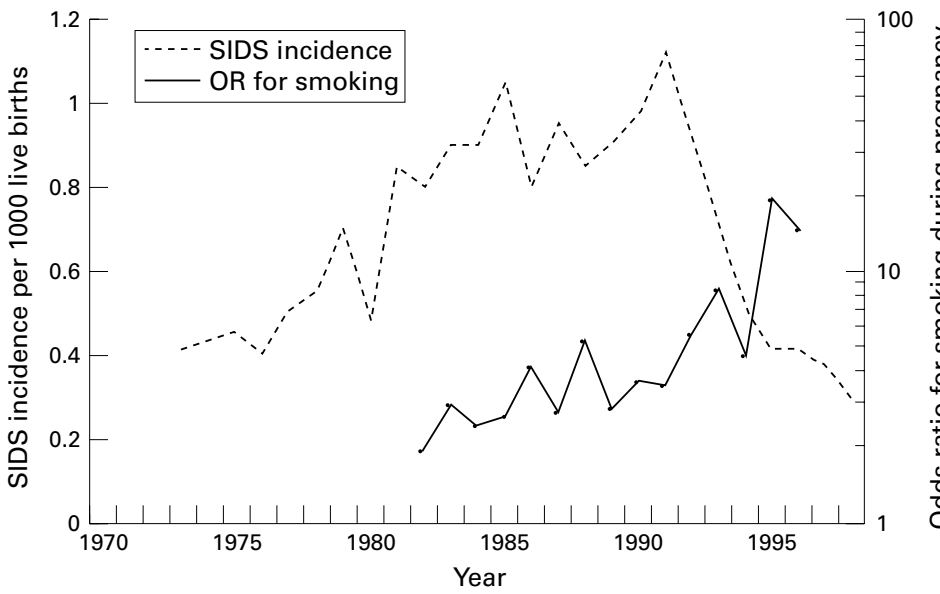

Figure 3 Odds ratios for smoking more than 10 cigarettes per day in early pregnancy (continuous line), and incidence of SIDS (dotted line) in Sweden, 1973-1996. Data from the Medical Birth Registry of Sweden. Smoking data available from 1982. than 38 weeks) increased from $15 \%$ to $29 \%$. Also, admissions to neonatal wards increased from $17 \%$ of the cases to $30 \%$.

The phenomenon of more babies dying at weekends did not show any change; $38 \%$ of all cases occurred on Saturday or Sunday, compared to the expected frequency of $28 \%$.

The proportion of young mothers (under 20 years) decreased significantly from $14 \%$ in the 1970 s to $5 \%$ in the 1990 s. High parity (three or more children) increased from $28 \%$ to $41 \%$. Cohabitation was as prevalent in the 1970 s as in the 1990s. The frequency of previous ALTEs, deaths outdoors, or recent common cold did not change. However, we could see a striking difference in the incidence of deaths in cars. In $1970-1980$ about $10 \%$ died in cars, compared with $1.7 \%$ in the early $1990 \mathrm{~s}$.

Figure 2 shows the distribution of SIDS cases in the three time periods by months of the year overlaid by the fitted cosine curve, and table 5 the details of the cosine function. We found no significant seasonality in the Norvenius (1970s) study, as opposed to 1984 and later.

CHANGING EFFECTS OF RISK FACTORS

The univariate odds ratios for smoking during early pregnancy and preterm birth increased significantly over the study period, while male sex, maternal age, parity, SGA, and combined SGA and preterm birth did not show any significant changes (table 2). This was confirmed in the multivariate models (table 3 which includes smoking in the model, and table 4 which excludes smoking) with the exception of the combination of SGA and preterm birth, where the odds ratio was significantly increased when adjusting for smoking during pregnancy (table 3 ).

When plotting the odds ratios for smoking against a background of SIDS incidence, we found that the odds ratio for SIDS when smoking more than 10 cigarettes per day had increased ( $\mathrm{p}<0.01$, Pearson's $\mathrm{R})$ from about 2 in 1982-1991 (smoking is not recorded in the Medical Birth Registry before 1981) to over 15 in 1995 and 1996 (fig 3). 


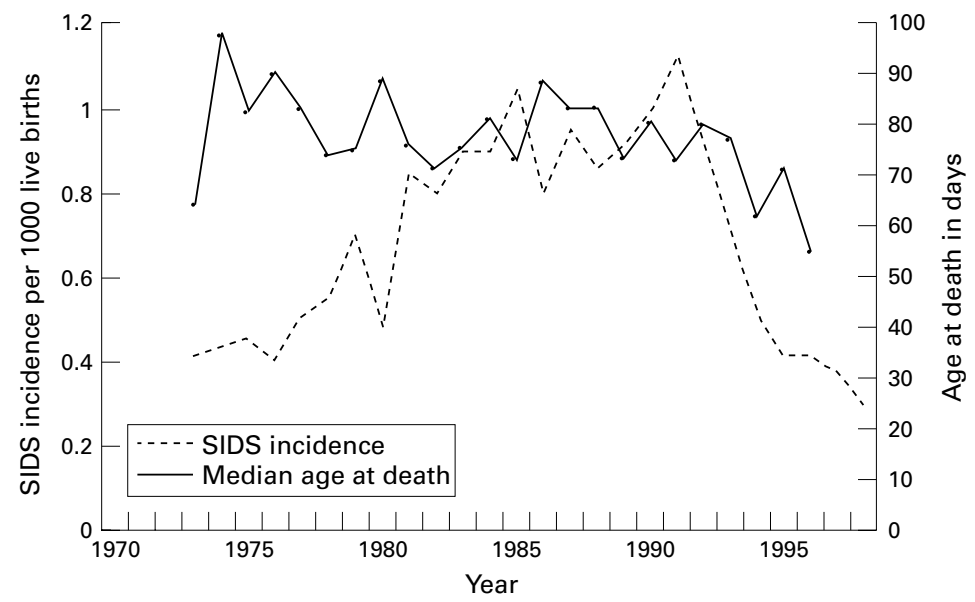

Figure 4 Median age at death (continuous line) by year and incidence of SIDS (dotted line) in Sweden, 1973-1996. Data from the Medical Birth Registry of Sweden.

Median age at death showed a significant $(\mathrm{p}<0.05)$ decrease, from about 90 days in the 1970 s to 60 days in the 1990 s (fig 4). The percentage of deaths at weekends remained constant at around $34 \%$ on Saturday to Sunday, and around $50 \%$ on Friday to Sunday, compared to the expected frequencies of $28 \%$ and $42 \%$, respectively. The difference was highly significant $(\mathrm{p}<0.001)$.

COSINOR ANALYSIS

In the cosinor analysis of the early Swedish studies (table 5), we found that seasonality was significant during the period of Wennergren's study (1984-1986), and during the NESS study period (1992-1995). In the MBR data there was a significant seasonal variation during the periods of rising (1973-1980) and high incidence (1981-1992) but not during the period of falling incidence after the risk reducing campaign (1993-1996).

Table 5 Cosinor analysis of incidence of sudden infant death syndrome in Sweden by periods of different incidence

\begin{tabular}{|c|c|c|c|c|c|c|c|}
\hline Period & $R$ & $a$ & $b$ & $c$ & $\begin{array}{l}\text { Maximum } \\
\text { events at } \\
\text { peak }\end{array}$ & Peak & $p$ value \\
\hline \multicolumn{8}{|l|}{ Part one } \\
\hline Norvenius & 0.405 & 28.376 & -3.581 & 2.718 & 32 & 25 Jan & $>0.2$ \\
\hline Wennergren et al & 0.777 & 5.848 & -4.884 & -3.375 & 11 & 13 Jan & $<0.01$ \\
\hline NESS & 0.750 & 9.916 & 3.124 & 0.771 & 13 & $20 \mathrm{Nov}$ & $<0.01$ \\
\hline \multicolumn{8}{|l|}{ Part two } \\
\hline 1973-1980 & 0.664 & 31.583 & -6.113 & -2.959 & 37 & $20 \mathrm{Dec}$ & $<0.02$ \\
\hline 1981-1992 & 0.951 & 100.833 & 49.740 & -44.236 & 150 & $15 \mathrm{Jan}$ & $<0.001$ \\
\hline 1993-1996 & 0.251 & 13.917 & 1.205 & 1.300 & 15 & $15 \mathrm{Oct}$ & $>0.2$ \\
\hline
\end{tabular}

Fitted function: $f(\phi)=a+b \cos (\phi+c)$.

$\mathrm{R}=$ correlation coefficient.

Table 6 Comparison between OR for risk factors for SIDS in the NESS (full Scandinavian data) and the Medical Birth Registry of Sweden 1993-1996

\begin{tabular}{|c|c|c|c|c|}
\hline \multirow[b]{2}{*}{ Risk factor } & \multicolumn{2}{|c|}{ NESS (1992-1995) } & \multicolumn{2}{|c|}{$M B R(1993-1996)$} \\
\hline & $O R$ & $95 \% C I$ & $O R$ & $95 \% C I$ \\
\hline Male sex & 1.8 & $0.6,4.9$ & 1.2 & $0.9,1.7$ \\
\hline Birth weight $<2500 \mathrm{~g}$ & 9.3 & $5.1,17$ & 5.7 & $3.8,8.7$ \\
\hline Gestation $<37$ weeks & 5.7 & $3.5,9.4$ & 4.8 & $3.2,7.2$ \\
\hline Smoking $10+\mathrm{cig} /$ day in early pregnancy & 12.3 & $5.6,27.0$ & 9.6 & $6.5,14.0$ \\
\hline Maternal age $<20$ years & 3.7 & $1.6,8.9$ & 3.1 & $1.5,5.6$ \\
\hline Not cohabitating parents & 2.9 & $1.7,5.0$ & 3.1 & $1.9,5.1$ \\
\hline
\end{tabular}

MAIN EFFECTS IN THE NESS AND MBR

When comparing the odds ratios and 95\% confidence intervals for known risk factors for SIDS in the NESS and the MBR of Sweden, we found that except for cohabitating parents, odds ratios were higher in the NESS than in the MBR, but that all confidence intervals were overlapping (table 6).

\section{Discussion}

As the studies of Wennergren et al and the NESS did not collect data from all cases of SIDS, there is a possibility of selection bias in these studies, in contrast to Norvenius and the Medical Birth Registry material. In the NESS, however, we found that the proportions of single mothers, young mothers, and first births were lower in the case-control data than in the Medical Birth Registry of Norway but to a similar extent in cases and controls. ${ }^{22}$ In a study of the controls in the Nordic study, ${ }^{23}$ we found that the proportion of mothers over 20 years of age, cohabitation with the father of the child, gestational ages between 38 and 42 weeks, and birth weights over $2500 \mathrm{~g}$ was higher among the NESS controls than in the total Nordic population, suggesting that, compared to vital statistics, these data contained more potentially healthy infants and infants with a more favourable social situation. However, the validity of the NESS is supported by the finding that there were no significant differences in odds ratios regarding important risk factors (table 6).

It could be hypothesised that the introduction of supine sleeping should cause a shift in age distribution towards higher age groups. The rationale for this would be that infants under 3-4 months of age, who are incapable of turning themselves, would benefit more from the change to supine sleeping position than older infants. However, we could not confirm such a hypothesis, but rather found a slightly falling median age over time (fig 4). However, in Norway between 1967 and 1995, no change in age at death has been found (Daltveit, personal commmunication).

Deaths in cars were very common in the 1970s and 1980s (approximately 10\%), but rarer in the $1990 \mathrm{~s}(1.7 \%)$. The most likely explanation for this is the change from placing the child prone in a carrycot in the back seat to sitting face turned to the driver, in a special child's seat attached to the front seat. Reports in the media of the dangers of car rides with very young infants may have contributed to increased parental attention.

The high incidence during weekends is a hitherto unexplained characteristic of SIDS. ${ }^{24-28}$ In 1969, von Sydow wrote, after examining eight cases, two of which had occurred on family birthdays, that the common pattern was that "... the baby was not in the centre of attention ...". ${ }^{26}$ A relation with alcohol debauches has been suggested, ${ }^{28}$ but the findings concerning alcohol are conflicting and marred by statistical uncertainty. ${ }^{29} 30$

Prone sleeping could not be assessed, since neither the papers by Norvenius and Wennergren et al nor the MBR contain information on 
sleeping position. In two previous papers, we have described the changes in ${ }^{11}$ and effects of ${ }^{13}$ the sleeping position during the NESS period (1992-1995).

The results from the comparison of SIDS cases and controls from the Medical Birth Registry of Sweden showed that there has been a change in effect of known risk factors. Sleeping position is not noted in the Medical Birth Registry, but we know from other sources that prone sleeping decreased in Scandinavia after the introduction of the risk reducing campaigns. ${ }^{11} 3132$ The finding of increasing odds ratios for smoking during pregnancy and premature birth is intriguing. In an earlier study, ${ }^{11}$ we could see that there was an increase in the odds ratios for prone sleeping, smoking, and bottle feeding during the study period of NESS, 1992-1995, although this could not be shown to be significant, presumably as a result of small numbers. As we commented earlier, the reason for this could be that, with the change in infants' sleeping position from prone to supine, SIDS cases might now be recruited from a group of infants with a higher prevalence of other risk factors. With the reintroduction of the supine sleeping position, risk factors that previously, during periods of lower incidence with supine as the preferred sleeping position, were more important, emerge again. We believe that the finding of an increased odds ratio for smoking in early pregnancy in both datasets supports this view. Furthermore, we have noted an increase in the univariate odds ratio for preterm birth from 2.2 to 5.0 in the NESS material (unpublished observation).

From this study, the most important risk factors seem to be smoking more than 10 cigarettes a day during early pregnancy and prematurity. For these, the odds ratios were almost doubled, and the confidence intervals did not overlap each other. Similar findings have been noted in the UK after the intervention. ${ }^{33}$

In this study, we could not confirm the findings from Norway, ${ }^{12}$ with increased effects of low maternal age and high birth order during decreasing SIDS incidence. The finding is somewhat puzzling, but illustrates the fact that differences exist between the countries. In a comparative study of infant mortality in Norway and Sweden between 1985 and 1988, it has been shown that the largest difference between Norway and Sweden was found in infants of young mothers with high birth order, ${ }^{34}$ which is consistent with our findings concerning SIDS.

Seasonality, with an increased incidence during winter and a decreased incidence during summer, has been considered a distinctive feature of SIDS. ${ }^{21}{ }^{35}$ This can be seen most easily in periods of high incidence, such as the 1980 s in Sweden. ${ }^{3}$ However, there seems to be a seasonal variation even in low incidence periods, ${ }^{236}$ although it is less discernible, especially when the numbers are as low as in the Nordic countries. This study confirms that statistically significant seasonality is a characteristic of periods with high incidence, but that seasonality cannot be shown in periods with low

\section{Key messages}

- SIDS incidence in Sweden declined from 1.1 per 1000 live births in 1991 to 0.3 in 1999

- The predominance of deaths at weekends remained

- Deaths in cars declined

- Age at death decreased from 90 to 60 days

- Seasonality was less notable in periods of low incidence

- Odds ratios increased for smoking and prematurity

incidence (table 5). The reason for the differences in seasonality between the studies of Norvenius, Wennergren et al, and NESS on the one hand, and the Medical Birth Registry on the other, is probably that the time periods are not identical. In order to get as large a dataset as possible for the analyses of the MBR material, these periods had to be extended beyond the time limits of the earlier studies. This resulted in the first period in the MBR dataset being more "high incidence" than the study of Norvenius, and the last more "low incidence" than the NESS study, thus giving different results regarding the significance in seasonality. Both Wennergren's material and the material from period II (1981-1992) in the MBR, though, show significant seasonality.

\section{CONCLUSIONS}

We found that age at death decreased from 90 to 60 days, the high incidence during weekends persisted, and seasonality was significant in high incidence periods but less discernible in low incidence periods. In recent years, the odds ratios have increased for smoking during pregnancy and prematurity.

Thus, in addition to the continuing promotion of supine sleeping, efforts must be concentrated on reducing smoking in fertile women and continuously improving the quality of maternal care to maintain and even lower the SIDS incidence in Scandinavia.

We would like to give special thanks to Petra Otterblad-Olausson for help with the SGA transformations and Max Köster for supplying data files (both at the Medical Birth Registry of Sweden). We thank project coordinator P Schreuder and data consultant S Nilssen at the Medical Birth Registry of Norway, for special help with data collection in NORDEPI, and the regional coordinators. This study was supported by grants from the Nordic Council, the Swedish Medical Research Council, the Medical Society of Göteborg, "Förenade Liv" Mutual Group Life Insurance Company, Stockholm, Sweden, the First of May Annual Flower Campaign, the Norwegian Research Council, the Swedish SIDS Parental Organisation, the Norwegian SIDS Parental Organisation, and the Danish SIDS Parental Organisation.

1 Petersson O, von Sydow G. Plötslig, oväntad spädbarnsdöd. [Sudden, unexpected infant death]. Soc Med Tidskr $1975 ; 52: 448-52$

2 Norvenius SG. Sudden infant death syndrome in Sweden in 1973-1977 and 1979. Acta Paediatr Scand Suppl 1987;333: $1-138$.

3 Wennergren G, Milerad J, Lagercrantz H, et al. The epidemiology of sudden infant death syndrome and attacks of lifelessness in Sweden. Acta Paediatr Scand 1987;76:898906.

4 Helweg-Larsen K, Øyen N, Milerad J, Irgens LM, Rognum TO. Sudden infant death in the Nordic countries. TemaNord. Report no. 600. København: Nordic Council of Ministers, December 1997. 
5 Engelberts AC, de Jonge GA. Choice of sleeping position for infants: possible association with cot death. Arch Dis Child 1990;65:462-7.

6 Fleming PJ, Gilbert R, Azaz Y, et al. Interaction between bedding and sleeping position in the sudden infant death syndrome: a population based case-control study. BMF

7 Mitchell EA, Scragg R, Stewart AW, et al. Results from the first year of the New Zealand cot death study. $N Z$ Med $\mathcal{F}$ 1991;104:71-6.

8 Markestad T. Information about sudden infant death syndrome for the general public. Acta Paediatr Suppl 1993; 389:124-5.

9 Helweg-Larsen K, Lundemose JB, Bille H. [Overheating and sudden infant death. Temperature regulation in relation to the prone position, the possible pathogenesis of sudden infant death]. Ugeskr Laeger 1994;156:7193-6.

10 Swedish National Board of Health and Welfare. Guidelines on infant sleep position. Sweden: The Swedish National Bn infant sleep position. Sweden:

11 Wennergren G, Alm B, Øyen N, et al. The decline in the incidence of SIDS in Scandinavia and its relation to
risk-intervention campaigns. Nordic Epidemiological risk-intervention campaigns. Nordic E
SIDS Study. Acta Paediatr 1997;86:963-8.

12 Daltveit AK, Øyen N, Skjaerven R, Irgens LM. The epidemic of SIDS in Norway 1967-93: changing effects of risk factors. Arch Dis Child 1997;77:23-7.

13 Øyen N, Markestad T, Skjærven R, et al. Combined effects of sleeping position and prenatal risk factors in sudden infant death syndrome: the Nordic Epidemiologial SIDS Study. Pediatrics 1997;100:613-21.

14 NOMESCO. Fødsler og spcedbørnsdødelighed $i$ de nordiske lande. [Births and infant mortality in the Nordic countries]. Copenhagen: NOMESCO, 1993.

15 Fødsler i Norden. Medicinsk fødselsregistrering. (Births in the Nordic countries. Registration of the outcome of pregnancy) Nordic countries. Registration of the outcome of
1979-1983. Reykjavik: Offsetmyndir h. f., 1987.

16 Dean JA, Coulombier D, Smith DC, Brendel KA, Arner TG, Dean AG. EpiInfo, 6th edn. Atlanta: Centers for DisTG, Dean AG. EpiInfo, 6th edn. At

17 Altman D. Comparing groups-categorical data. In: Practical statistics for medical research. London: Chapman and Hall cal statistics for

18 Norusis M. SPSS for Windows. Advanced statistics. Release 6.0. Chicago: SPSS Inc., 1993.

19 Marsal K, Persson PH, Larsen T, Lilja H, Selbing A, Sultan B. Intrauterine growth curves based on ultrasonically estimated foetal weights. Acta Paediatr 1996;85:843-8.

20 Hallberg F, Johnson E, Nelson W, Runge W, Sothern R. Autorhythmometry-procedures for physiologic self-
measurements and their analysis. Physiol Teach 1972;1: $1-11$.
21 Douglas AS, Helms PJ, Jolliffe IT. Seasonality of sudden infant death syndrome (SIDS) by age at death. Acta Paediatr 1998;87:1033-8.

22 Alm B, Milerad J, Wennergren G, et al. A case-control study of smoking and sudden infant death syndrome in the Scandinavian countries, 1992 to 1995. The Nordic Epidemiological SIDS Study. Arch Dis Child 1998;78:329-34.

23 Alm B, Norvenius SG, Wennergren G, et al. Living conditions in early infancy in Denmark, Norway and Sweden 1992-95. Results from the Nordic Epidemiological SIDS study. Acta Paediatr 2000;89:208-14.

24 Emery JL. Epidemiology of "sudden, unexpected or rapid" deaths in children. BMF 1959;2:925-8.

25 Cameron AH, Asher, P. Cot deaths in Birmingham 1958-61. Med Sci Law 1965;5:187.

26 von Sydow G. Plötslig, oväntad spädbarnsdödSocialmedicinsk värdering av några fall. [Sudden unexpected death in infants-socio-medical evaluation of some cases]. Läkartidningen 1969;66:683-9.

27 Kaada B, Sivertsen E. Sudden infant death syndrome during weekends and holidays in Norway in 1967-1985. Scand F Soc Med 1990;18:17-23.

28 Williams SM, Mitchell EA, Scragg R. Why is sudden infant death syndrome more common at weekends? The New Zealand National Cot Death Study Group. Arch Dis Child 1997;77:415-19.

29 Scragg R, Mitchell EA, Taylor BJ, et al. Bed sharing, smoking, and alcohol in the sudden infant death syndrome. New Zealand Cot Death Study Group. BMF 1993;307:1312-18.

30 Alm B, Wennergren G, Norvenius G, et al. Caffeine and alcohol as risk factors for sudden infant death syndrome. Arch Dis Child 1999;81:107-11.

31 Andersen F, Forsdahl A. [Change in infants' sleeping position and incidence of crib death in Northern Norway]. Tidsskr Nor Laegeforen 1995;115:3515-17.

32 Irgens LM, Markestad T, Baste V, Schreuder P, Skjaerven $\mathrm{R}$, Øyen N. Sleeping position and sudden infant death syndrome in Norway 1967-91. Arch Dis Child 1995;72:47882.

33 Wigfield R, Gilbert R, Fleming PJ. SIDS: risk reduction measures. Early Hum Dev 1994;38:161-4.

34 Espehaug B, Daltveit AK, Vollset SE, Øyen N, Ericson A, Irgens LM. Infant survival in Norway and Sweden 1985-88. Acta Paediatr 1994;83:977-82.

35 Banks AL. Enquiry into sudden death in infancy. Report no. 113. London: HMSO, 1965.

36 Julious SA. There is still seasonality in sudden infant death syndrome in England and Wales. F Epidemiol Community Health 1997;51:101-2. 